\title{
Performed Lesion Description
}

National Cancer Institute

\section{Source}

National Cancer Institute. Performed Lesion Description. NCI Thesaurus. Code C93429.

The completed characterization of the extent of any localized or abnormal change in the structure of part of an organ or tissue. 